J. Hugh Devitt MD MSc FRCPC, David A. Brooks EMCA(P), Peter A. Oakley MB ChB FFARCS, Peter M. Webster MD FRCPC

\section{Mask lung ventilation by ambulance personnel: a perform- ance assessment}

We evaluated the ability of basic life support ambulance officers and anaesthetists to perform lung ventilation with a face mask. After induction of anaesthesia and institution of standardized airway conditions the ambulance officer or anaesthetist placed a mask on the patient's face and lung ventilation was commenced. The order of hand grip (one vs two hands) was randomized. The mask was connected to a ventilator. which had flow and pressure transducers in the inspiratory and expiratory breathing circuits. The output of these devices was sent to an electronic integrator to determine volumes. Calibration of the flow transducers was made against a spirometer while ventilating a test lung. Oesophageal insufflation was determined by listening over the epigastrium with a stethoscope. Data collected included presence of gastro-oesophageal insufflation, inspiratory and expiratory volumes. Expiratory volumes for ambulance officers and anaesthetists at $30 \mathrm{~cm} \mathrm{H}_{2} \mathrm{O}$ were greater than that of ambulance officers at $20 \mathrm{~cm} \mathrm{H} \mathrm{H}_{2} \mathrm{O}(P<0.001)$ but profession of the mask holder or hand grip had no effect on expiratory volume. There was no difference in the mask leak when the professions were compared but ambulance officers had a lower mask leak with a two-handed grip at $20 \mathrm{~cm} \mathrm{H}_{2} \mathrm{O}(P<0.001)$. Anaesthetists had a greater incidence of gastro-oesophageal insufflation when a two-handed mask grip was utilized $(P<$

\section{Key words}

AIRWAY MANAGEMENT: mask ventilation;

EQUIPMENT: airway, masks, anaesthesia;

MANPOWER: anaesthetists, ambulance officers;

VENTILATION: artificial resuscitation.

From the Departments of Anaesthesia, Emergency Medicine, and the Division of Respiratory Medicine, Sunnybrook Health Science Centre, University of Toronto.

Address correspondence to: Dr. J. Hugh Devitt, Department of Anaesthesia, C-818, Sunnybrook Health Science Centre, 2075 Bayview Avenue, Toronto, Ontario M4N 3M5.

This study was supported by a grant from the Ministry of Health of Ontario.

Presented in part at the annual meeting of The Canadian Anaesthetists' Society, Toronto, June 1992.

Accepted for publication 6th October, 1993.
0.05). In healthy relaxed patients there appeared to be little difference between the ambulance officers and qualified anaesthetists in airway maintenance or mask-holding ability.

Cette étude a pour objectif l'évaluation de l'habileté des ambulanciers et des anesthésistes à réaliser la ventilation pulmonaire avec une masque facial. Après l'induction de l'anesthésie, l'ambulancier ou l'anesthésiste place un masque sur le visage du patient et commence la ventilation. L'ordre de l'utilisation de la façon de tenir le masque (une ou deux mains) est randomisée. Le masque est branché à un ventilateur équipé de transducteurs de mesure de débit et de pression placés sur les branches inspiratoire et expiratoire du circuit. Le débit de ces dispositifs est transmis à un intégrateur qui détermine les volumes. Les transducteurs de débit sont calibrés par spirométrie sur un poumon artificiel. Lïnsufflation de l'oesophage est déterminée par auscultation de l'épigastre. Les données receuillies comprennent la présence d'insufflation gastro-oesophagienne et les volumes inspiratoires et expiratoires. Les volumes expiratoires engendrés par les anesthésistes et les ambulanciers à 30 $\mathrm{cm} \mathrm{H}_{2} \mathrm{O}$ sont plus grands que ceux des ambulanciers $\dot{a} 20$ cm $\mathrm{H}_{2} \mathrm{O}(\mathrm{P}<0.001)$ mais la profession de celui qui tient le masque n'a pas d'effet sur les volumes expiratoires. Limportance de la fuite n'est pas différente entre professions mais elle est moins importante pour les ambulanciers lorsquils tiennent le masque à deux mains à $20 \mathrm{~cm} \mathrm{H}_{2} \mathrm{O}(\mathrm{P}<0,001)$. Plus d'air pénètre dans l'estomac et l'oesophage quand les anesthésistes tiennent le masque à deux mains $(P<0,05)$. Chez des patients bien portants, il y a peu de différence entre l'habileté des ambulanciers et celles des anesthésistes qualifiés à maintenir lintégrité des voies respiratoires et leurs façons de tenir le masque.

Basic life support ambulance officers are not trained to perform tracheal intubation, and therefore must rely on lung ventilation by mask for patients with apnoea or depressed ventilation. These individuals must perform lung ventilation with a bag valve mask (BVM) device during life-threatening circumstances. Past investigations suggest that pulmonary ventilation with BVM devices leads to inadequate pulmonary ventilation during cardiopulmonary resuscitation. ${ }^{1-3}$ One of the causes for failure of 
BVM devices to deliver adequate ventilation would appear to be difficulty in maintaining a mask seal on the patient's face. ${ }^{47}$ However, these studies have been performed on mannequins or lung models and not on patients. We undertook a study to measure the proficiency of basic life support ambulance officers with the skills of maintaining an airway and holding a mask on a patient's face during positive-pressure ventilation.

\section{Methods}

Patients of the American Society of Anesthesiologists (ASA) classification of physical status I or II, undergoing elective surgical procedures that would normally involve tracheal intubation, were studied. Exclusion criteria are listed in Table I. Informed consent was obtained from each patient on the night before surgery and permission to study the patient was requested from the surgeon concerned. The premedication of patients was left to the discretion of each patient's anaesthetist. The study had the approval of the institutional ethics committee.

Basic life support ambulance officers with at least five years experience were contacted on the day before the study and arrangements were made for them to be in the operating room (OR) the following day. The ambulance officers were admitted to the OR before the induction of anaesthesia. In the $O R$ an intravenous infusion was established by the anaesthetist and standard monitoring devices were attached. After baseline physiological measurements, anaesthesia was induced with a technique left to the discretion of the patient's anaesthetist. Neuromuscular blockade was achieved using a nondepolarizing muscle relaxant. After induction of anaesthesia, mask ventilation was performed by the anaesthetist with $100 \%$ oxygen and isoflurane. An oropharyngeal airway was inserted by the anaesthetist, and airway patency was confirmed with gentle manual ventilation. Adequacy of neuromuscular blockade was assessed with a peripheral nerve stimulator. The ambulance officer was handed a Solco \#5 adult mask (Laerdal mask) attached to the measuring equipment. The ambulance officer then seated the mask on the patient's face and manipulated the head and neck to achieve what was felt to be the best possible airway. The mask was connected to a Siemens Servo$\mathrm{C}$ ventilator and ventilation was commenced with a square wave form in the pressure-controlled mode. The Siemens Servo-C ventilator contains separate pressure and flow transducers in both the expiratory and inspiratory limbs of the breathing circuit. Low compliance, wide bore tubing was used, and all connections were checked for leaks.

Positive pressure ventilation took place with $100 \%$ oxygen and isoflurane as directed by the anaesthetist. Patients were randomized to receive one of two pressure settings
TABLE I Exclusion criteria

1 Acute or chronic pulmonary disease as defined by an ASA status of III or higher.

2 Upper airway abnormalities which potentially made intubation difficult and/or precluded the use of neuromuscular blocking agents.

3 Gastro-oesophageal reflux or other gastric or oesophageal abnormalities that mandated a rapid-sequence induction technique.

4 Food or drink within six hours of surgery.

5 Ischaemic or congenital heart disease.

6 Pregnancy.

7 Facial hair such as a beard or mustache.

(either 20 or $30 \mathrm{~cm} \mathrm{H}_{2} \mathrm{O}$ ) at a rate of ten breaths $\cdot \mathrm{min}^{-1}$. The order of hand grip on the mask (one versus two hands) was also randomized on each patient to eliminate any variables due to the timing of ventilation. Measurements were taken over ten breaths at each mask hand grip. An inspiratory to expiratory ratio of $1: 5$ was used to allow adequate emptying during the expiratory phase.

Flow and pressure transducers were placed in the inspiratory and expiratory limbs of the breathing circuit. The output of these devices was sent to an electronic integrator to determine inspiratory and expiratory volumes. The flow signal, inspiratory and expiratory volumes, and airway pressure were recorded on a computer disk via an analog to digital converter. As well, oesophago-gastric insufflation was qualitatively assessed by listening over the epigastrium with a stethoscope during ventilation. Gastro-oesophageal insufflation was determined to be present when it was heard over each breath of the study period. Once the data had been collected from both mask hand grip techniques, the anaesthetist then intubated the trachea and the anaesthetic and the operation were allowed to proceed.

A second group of patients was studied with Royal College of Physicians and Surgeons of Canada certified anaesthetists holding the mask. A ventilation pressure of $30 \mathrm{~cm} \mathrm{H}_{2} \mathrm{O}$ was used in order to maximize any difference in mask leak that might occur between anaesthetists and ambulance personnel. However, the order of the mask grip (one versus two hands) was randomized on each patient. Data collection and study design were otherwise the same for anaesthetists as for ambulance officers.

For both of the mask grip techniques, data collected included airway pressure, inspiratory and expiratory volumes and whether air was heard to enter the stomach. Once data collection had occurred, calibration of the inspiratory and expiratory flow transducers was made against a spirometer while ventilating a test lung. The inspiratory and expiratory volumes were corrected with the calibration volumes. Leak was determined by subtracting the expiratory from the inspiratory volume. The 
TABLE II Demographic data of patients

\begin{tabular}{llll}
\hline & \multicolumn{2}{l}{ Ambulance } & \\
\cline { 2 - 3 } & $20 \mathrm{~cm} \mathrm{H} \mathrm{H}_{2} \mathrm{O}$ & $30 \mathrm{~cm} \mathrm{H} \mathrm{H}_{2} \mathrm{O}$ & $\begin{array}{l}\text { Anaesthetists } \\
30 \mathrm{~cm} \mathrm{H} \mathrm{H}_{2} \mathrm{O}\end{array}$ \\
\hline$n$ & 31 & 24 & 21 \\
Male/female & $16: 15$ & $13: 11$ & $14: 7$ \\
Age (mean $\pm \mathrm{SD})$ & $47.5 \pm 16.6$ & $46.6 \pm 17.2$ & $46.3 \pm 17.1$ \\
Age range & $21-79$ & $18-79$ & $21-74$ \\
\hline
\end{tabular}

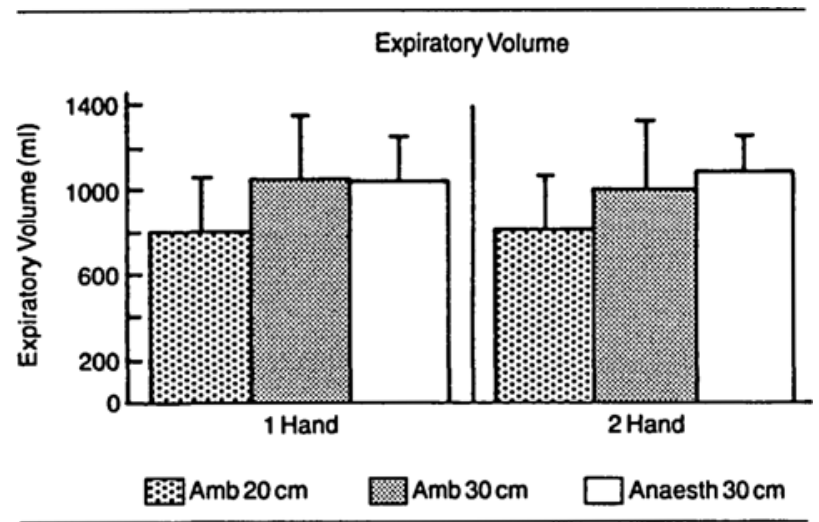

FIGURE 1 Comparison of expiratory volume of ambulance officers at 20 and $30 \mathrm{~cm} \mathrm{H}_{2} \mathrm{O}$ and anaesthetists at $30 \mathrm{~cm} \mathrm{H}_{2} \mathrm{O}$ inflation pressures with a one or two handed grip. Volumes are expressed as means with standard deviation represented by the bars. Higher inflation pressure resulted in greater expiratory volumes $(P<0.001)$.

leak was expressed as a fraction of the inspiratory volume. Leak calculated by this method would include any gas escaping to the stomach.

Age was compared by a one-way analysis of variance while sex ratio was compared with chi square analysis. Leak and expiratory volumes at 20 and $30 \mathrm{~cm} \mathrm{H}_{2} \mathrm{O}$ inflation pressure in ambulance personnel and at $30 \mathrm{~cm} \mathrm{H}_{2} \mathrm{O}$ inflation pressure in anaesthetists were compared with hand grip by a two-way analysis of variance. Frequency of gastric insufflation was compared by chi square analysis.

\section{Results}

Twenty-four ambulance officers were studied on 31 patients at $20 \mathrm{~cm} \mathrm{H}_{2} \mathrm{O}$ and 24 patients at $30 \mathrm{~cm} \mathrm{H}_{2} \mathrm{O}$, while 21 anaesthetists were studied on 21 patients at $30 \mathrm{~cm}$ $\mathrm{H}_{2} \mathrm{O}$ ventilation pressure over $16 \mathrm{mo}$. Demographic data are presented in Table II. There were no differences in the age or sex ratios in the three groups of patients studied.

Expiratory volumes for ambulance officers and anaesthetists at ventilation pressures of $30 \mathrm{~cm} \mathrm{H}_{2} \mathrm{O}$ were greater than at $20 \mathrm{~cm} \mathrm{H}_{2} \mathrm{O}(P<0.001)$ (Figure 1). However, there was no difference in expiratory volume achieved between anaesthetists and ambulance officers at $30 \mathrm{~cm}$ $\mathrm{H}_{2} \mathrm{O}$. Hand grip did not have any effect on expiratory

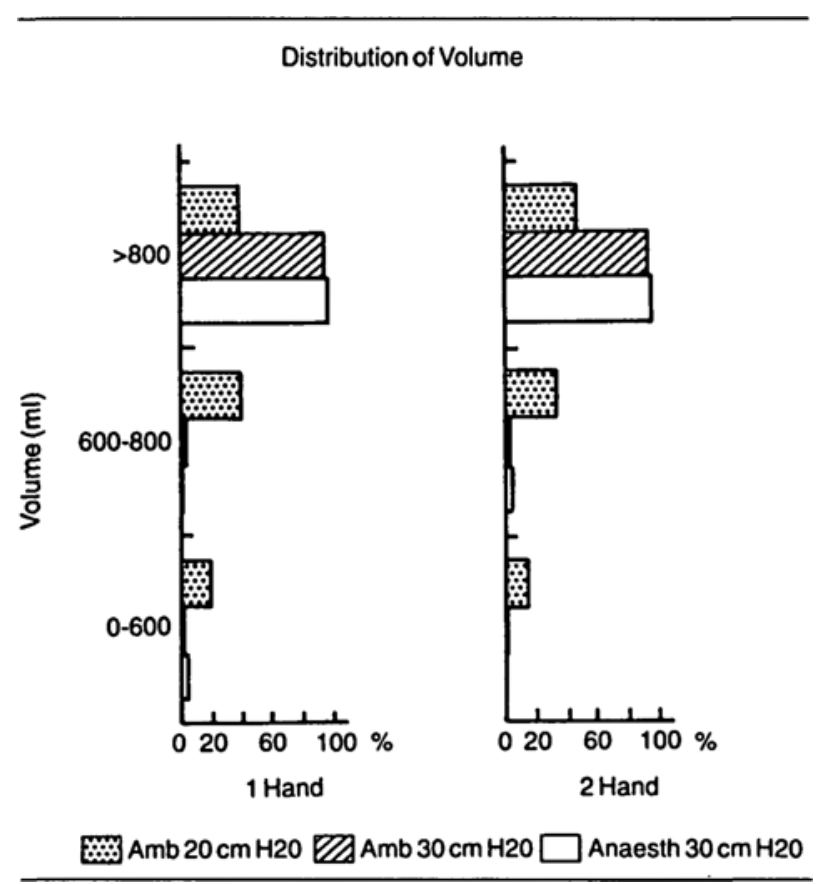

FIGURE 2 Distribution of expiratory volume of ambulance officers at 20 and $30 \mathrm{~cm} \mathrm{H}_{2} \mathrm{O}$ and anaesthetists at $30 \mathrm{~cm} \mathrm{H}_{2} \mathrm{O}$ inflation pressure with a one or two handed grip. Volumes are expressed as means. At $20 \mathrm{~cm} \mathrm{H}_{2} \mathrm{O}$ more than half of the lungs were ventilated with less than $800 \mathrm{ml}$.

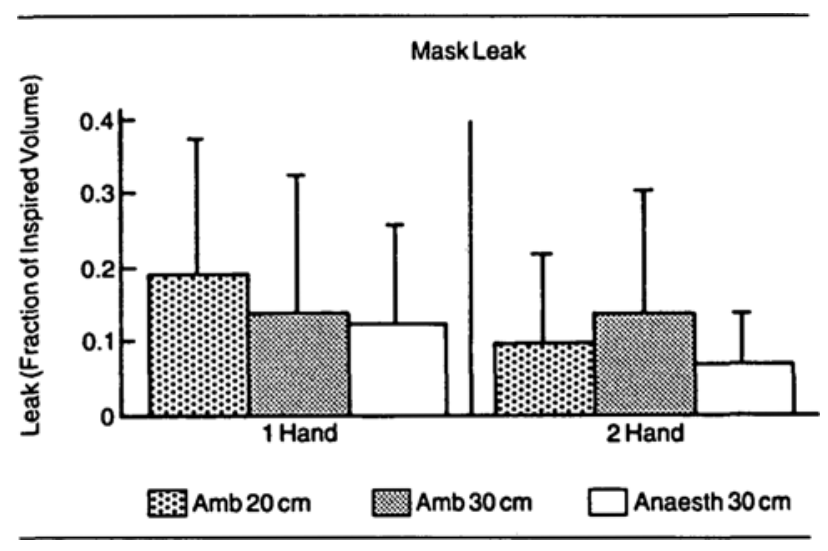

FIGURE 3 Comparison of leak fractions of ambulance officers at 20 and $30 \mathrm{~cm} \mathrm{H}_{2} \mathrm{O}$ and anaesthetists at $30 \mathrm{~cm} \mathrm{H}_{2} \mathrm{O}$ inflation pressures with a one or two handed grip. Leak fractions are expressed as means with standard deviation represented by the bars. There was a smaller leak fraction with a two handed grip $(P<0.01)$.

volume. At $20 \mathrm{~cm} \mathrm{H} \mathrm{H}_{2} \mathrm{O}$ more than half of the lungs were ventilated with less than $800 \mathrm{ml}$. The use of the oneor two-handed mask grip did not alter the number of patients' lungs ventilated with less than $800 \mathrm{ml}$ (Figure 2).

Leak, expressed as a fraction of the inspired volume, tended to be lower with anaesthetists but this difference was not statistically significant (Figure 3 ). There was a 
smaller leak with a two-handed grip, particularly with ambulance officers at $20 \mathrm{~cm} \mathrm{H}_{2} \mathrm{O}$ and anaesthetists $(P$ $<0.01$ ). The differences in hand grip was groupdependent as no difference in hand grip and mask leak was seen in ambulance officers at $30 \mathrm{~cm} \mathrm{H}_{2} \mathrm{O}$.

The frequency of gastro-oesophageal insufflation was greater with anaesthetists utilizing a one-handed grip ( $P$ $<0.05$ ) but the differences were not statistically significant when a two-handed mask grip was utilized (Figure 4).

\section{Discussion}

Mask type, degree of relaxation, ventilation pressure and ventilatory wave form were all controlled in this study. When ambulance officers and anaesthetists were evaluated within the confines of the study, there was little difference in the amount of leak around the mask or gastric insufflation. Not surprisingly, greater inflation pressure resulted in a larger volume of expired gas and a two-handed mask grip tended to have a lesser leak. With ambulance officers holding the mask, and utilizing ventilation pressures of $20 \mathrm{~cm} \mathrm{H}_{2} \mathrm{O}$, more than $50 \%$ of patients had an exhaled volume of less than the American Heart Association (AHA) standard of $800 \mathrm{ml} .{ }^{8}$ There was little difference in the incidence of gastro-oesophageal insufflation with the exception of anaesthetists utilizing a one-handed grip. We determined oesophago-gastric insufflation by qualitative means and were unable to measure the amount of air entering the stomach. Lawes and coworkers have suggested that it is possible to detect as little as $5 \mathrm{ml}$ of air entering the stomach with a stethoscope placed over the epigastrium. ${ }^{9}$

Low exhaled volumes occurred, independent of hand grip and despite controlled and adequate ventilation supplied by a mechanical ventilator. Others have had similar findings with a face mask and BVM devices. ${ }^{1-7}$ The aetiology of inadequate ventilation has been attributed to an inadequate mask seal against the patient's face or an inability to develop an adequate bag compression. ${ }^{6}$ Prolonging the I:E ratio may have resulted in higher exhaled volumes. Increasing airway pressure would likely result in a greater mask leak and an increased likelihood of gastro-oesophageal insufflation increasing the possibility of regurgitation and aspiration.

Our study eliminated the bag compression aspect of ventilation, and concentrated on the seal of the mask against the patient's face. Using paramedics as test subjects, Johannigman et al. compared several techniques of emergency ventilation including mouth to mouth, mouth to mask, and two masks with portable ventilators, utilizing a mannequin attached to a test lung. ${ }^{3}$ The volumes achieved by mechanical ventilators in Johannigman's study were comparable to our results. Our findings

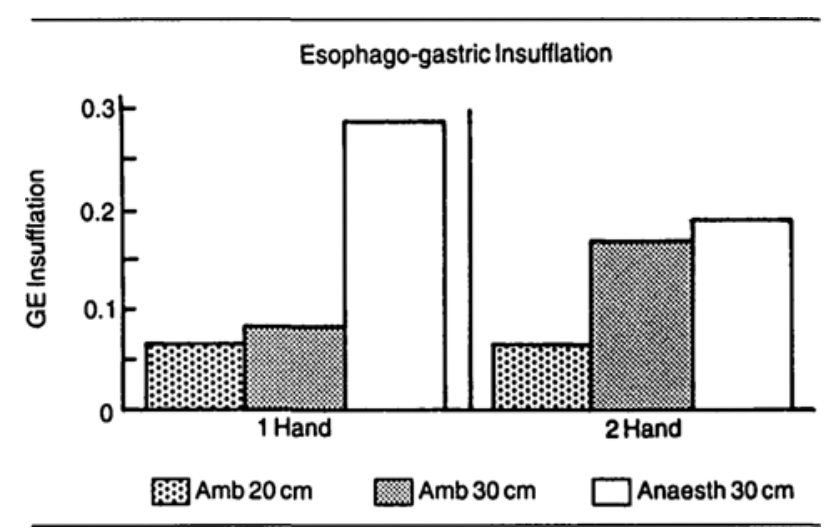

FIGURE 4 Comparison of the incidence of gastro-oesophageal insufflation of ambulance officers at 20 and $30 \mathrm{~cm} \mathrm{H}_{2} \mathrm{O}$ and anaesthetists at $30 \mathrm{~cm} \mathrm{H} \mathrm{H}_{2} \mathrm{O}$ inflation pressures with a one or two handed grip. The incidence of gastro-oesophageal insufflation is expressed as a mean. The frequency of gastro-oesophageal insufflation was greater with anaesthetists utilizing a one handed grip $(P<0.05)$.

suggest that mask leak, and not bag compression, is the chief cause of reduced ventilation with BVM devices.

When ambulance officers performed mask ventilation, leak ranged from 10-19\% depending on ventilation pressure and hand grip in our study. In a mannequin and test lung model, Stewart $e t$ al. calculated mask leak at two different lung compliances using a wide range of different medical personnel. At a lung compliance of 0.01 $\mathrm{L} \cdot \mathrm{cm}^{-1} \mathrm{H}_{2} \mathrm{O}$ with a Laerdal mask, leak expressed as a fraction of total ventilation was $40 \%$. Of the three masks evaluated in Stewart's study, the Laerdal mask was associated with the greatest leak. ${ }^{4}$

Few studies have compared ambulance officers with physicians in basic airway manoeuvres. Ambulance officers have been compared with emergency room physicians when ventilating a test lung with an endotracheal tube and a BVM device. Ambulance officers and physicians achieved similar volumes at similar inflation pressures. ${ }^{10}$ This would suggest that the ability to squeeze the bag is not profession-dependent. There was little difference between ambulance officers and qualified anaesthetists in airway maintenance or mask-holding ability in our study. We chose anaesthetists as our comparison group because we felt anaesthetists by the nature of their training and practice would represent a suitable gold standard.

Our study has several flaws. The study was conducted in highly artificial and ideal surroundings utilizing fully relaxed, healthy subjects. Excluded were many conditions that could alter pulmonary resistance and compliance and therefore potentially increase the amount of leak or gastro-oesophageal insufflation. Conditions in the field may be quite different. Pressure-controlled ventilation was used to ensure that ventilation pressures would be kept 
constant. This form of ventilation would maximize any leak as gas flow would continue during inspiration until the pressure limit was met. Despite this, there was little difference in mask leak.

This study suggests that the ambulance officers tested are adequately trained and perform these skills reasonably well. Further training is unlikely to improve performance. If ventilation volume is inadequate with BVM devices to meet current AHA standards, then tracheal intubation should be considered as a solution.

\section{Acknowledgments}

The authors would like to acknowledge the statistical guidance provided by Mr. Marko Katic. We would also like to thank Ms. Nancy Huntley for assistance with preparation of the manuscript.

\section{References}

1 Seidelin PH, Stolarek IH, Littlewood DG. Comparison of six methods emergency ventilation (Letter). Lancet 1986; 2: 1274-5.

2 Lawrence PJ, Sivaneswaran N. Ventilation during cardiopulmonary resuscitation: which method? Med J Aust 1985; 143: 443-6.

3 Johannigman JA, Branson RD, Davis $K J$ r, Hurst JM. Techniques of emergency ventilation: a model to evaluate tidal volume, airway pressure, and gastric insufflation. $\mathbf{J}$ Trauma 1991; 31: 93-8.

4 Stewart RD, Kaplan R, Pennock B, Thompson F. Influence of mask design on bag-mask ventilation. Ann Emerg Med 1985; 14: 403-6.

5 Hess $D$, Baran $C$. Ventilatory volumes using mouth-tomouth, mouth-to-mask, and bag-valve techniques. Respiratory Care 1986; 31: 774-9.

6 Elling $R$, Politis $J$. An evaluation of emergency medical technicians' ability to use manual ventilation devices. Ann Emerg Med 1983; 12: 765-8.

7 Harrison RR, Maull KI, Keenan RL, Boyan CP. Mouthto-mask ventilation: a superior method of rescue breathing. Ann Emerg Med 1992; 11: 74-6.

8 Anonymous Standards and guidelines for cardiopulmonary resuscitation (CPR) and emergency cardiac care (ECC). Part II: Adult basic life support. JAMA 1986; 255: 2905-32.

9 Lawes EG, Campbell I, Mercer D. Inflation pressure, gastric insufflation and rapid sequence induction. $\mathrm{Br} J$ Anaesth 1987; 59: 315-8.

10 Augustine $J A$, Seidel $D R, M c C a b e J B$. Ventilation performance using a self-inflating anesthesia bag: effect of operator characteristics. Am J Emerg Med 1987; 5: 267-70. 